\title{
The infant feeding practices of mothers in the Maldives
}

\author{
R Abdulraheem ${ }^{1}$ and CW Binns ${ }^{2, *}$ \\ ${ }^{1}$ Faculty of Health Sciences, Maldives College of Higher Education, Male', Republic of Maldives: ${ }^{2}$ School of Public \\ Health, Curtin University of Technology, GPO Box U1987, Perth, Western Australia 6845, Australia
}

\begin{abstract}
Objective: To document the infant feeding practices of Maldivian mothers. Methods: A cross-sectional survey of 251 Maldivian mothers recruited in 2004 from the 'well baby' or 'well child' clinics on the island of Male' and including 75 mothers from three other islands, Hura, Himmafushi and Thulusdhoo.

Results: The full breast-feeding rate at hospital discharge was 93\% but declined to $41 \%$ at 4 months. Any breast-feeding rates were high among Maldivian mothers: $100 \%$ at 1 month and 85\% were still breast-feeding at 6 months. The median duration of breast-feeding was 24 months.

Conclusion: Breast-feeding rates are high and the average duration of breast-feeding is more than 2 years in the Maldives. Health promotion activities should be directed towards maintaining the already high 'any breast-feeding' rates and increasing the proportion of infants exclusively breast-fed to 6 months.
\end{abstract}

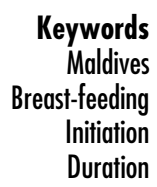

There have been few published health or nutrition studies from the Maldives and a literature search did not show any previous published studies of breast-feeding. While breast-feeding rates were high, the exclusive breastfeeding rate on leaving hospital in the Maldives was reported by the United Nations Children's Fund to be only $10 \%$ compared with $84 \%$ in Sri Lanka, the nearest large country $^{16}$. This rate is low compared with developed countries such as Australia, where the exclusive breastfeeding rate was $69 \%$ on discharge from hospital ${ }^{17}$.

The objective of the present study was to document breast-feeding rates in the Maldives and the factors that are important in breast-feeding initiation and duration. This will provide information to use in developing future health promotion programmes and allow the monitoring of infant feeding practices.

\section{Methods}

A cross-sectional survey was undertaken in 2004 of Maldivian mothers living on the island of Male' and on several outlying islands. Mothers were asked to complete a questionnaire based on questions originally used in the Perth Infant Feeding Study ${ }^{18,19}$. The questionnaire was translated into Dhivehi and back-translated to ensure literal and cultural understanding. The study was approved by the Human Research Ethics Committees of Curtin University of Technology and the Institute of Health Sciences, Male'. A sample of 176 Maldivian mothers was recruited from the 'well baby' or 'well child' clinics on the island of Male' and another 75 mothers from clinics on three other islands, Hura, Himmafushi and Thulusdhoo, a 
total of 251 mothers. The details of the study were explained to the mothers and informed consent was obtained before they were asked to complete the questionnaire. The inclusion criterion for mothers was that they had given birth within the past four years, similar to the criteria used for the breast-feeding questions of the Australian National Health Survey $2001^{20}$.

The questions provided information on infant feeding, including the duration of breast-feeding, the time of introduction of formula, cow's milk and solid foods, and factors influencing feeding methods. Sociodemographic characteristics included household income, parental education, marital status and occupation of the parents.

Data were analysed using the Statistical Package for the Social Sciences (SPSS for Windows version 12.0; SPSS Inc.). Two categories of breast-feeding were considered, i.e. 'any breast-feeding' and 'full breast-feeding'. The 'any breast-feeding' category included all infants fed any human breast milk. 'Full breast-feeding' included no supplemental formulas and/or cow's milk, aside from occasional water or medication.

\section{Results}

The demographic details of the sample are shown in Table 1 . The mean age of the mothers was 27 (range 19 to 43) years. Almost all of the mothers were literate, the

Table 1 Sociodemographic characteristics of Maldivian mothers $(n=251)$

\begin{tabular}{lr}
\hline Characteristic & $\%$ \\
\hline Age (years) & \\
$19-25$ & 42.4 \\
$26-30$ & 36.4 \\
$31-35$ & 16.8 \\
$36-43$ & 3.6 \\
Level of education & 10.4 \\
Basic education & 33.5 \\
Primary school & 44.6 \\
Secondary school & 10.4 \\
Senior high school and over & \\
Marital status & 95.2 \\
Married & 3.2 \\
Divorced & 44.6 \\
Occupation & 55.4 \\
Housewife & \\
Employed & 95.2 \\
Occupation of spouse & 4.8 \\
Employed & \\
Unemployed & 13.9 \\
Total family income for the past 12 months (Rufiyaa) & \\
Less than 15000 & 46.6 \\
Between 15000 and 40000 & 18.4 \\
Between 40 000 and 60000 & 18.7 \\
More than 60000 & \\
Island where the mother is living & 70.1 \\
Male' & 13.1 \\
Hura & 8.0 \\
Himmafushi & 8.8 \\
Thulusdhoo & \\
\hline &
\end{tabular}

* At the time of the survey, $\$$ US $1=12.75$ Maldivian Rufiyaa. majority had attended some high school and 95\% were married. Just over half of the mothers (55\%) were employed outside the household and almost all of their spouses were in formal employment (95\%).

About half of the mothers (53\%) put their infants to the breast immediately after birth (Table 2). When breast-feeding was delayed for more than a few hours it was usually due to having had a Caesarean section. While the 'full breast-feeding' rate was initially high, $93 \%$ at 1 month and $41 \%$ at 4 months, no infant was being fully breast-fed at the age of 6 months (Fig. 1). However, the 'any breast-feeding' rate remained high in Maldivian mothers and, at 12 months, 61\% of mothers continued to breast-feed, declining to $49 \%$ at 24 months. The median duration of 'any breast-feeding' was 24 months. About one-third of mothers were still breast-feeding at 3 years. There were no significant differences between boys and girls in breast-feeding initiation or duration.

In a very small number of cases, formula was given to babies as early as 1 month, usually while breast-feeding was being continued (Fig. 2). The earliest reported age that Maldivian mothers gave their infants cow's milk was 7 months. By 6 months of age 30\% of mothers were giving water to their infants on a regular basis. Maldivian mothers introduced solid foods to their infants, including wheat, rice, fruits, vegetables and manufactured food, quite early (median age 4.5 months) (see Fig. 3 for cumulative percentage).

In the opinion section of the questionnaire (Tables 3 and 4), the mothers in the survey were asked to select from a number of statements about breast-feeding and hence could give more than one response. When asked why they thought Maldivian mothers stop breast-feeding before 6 months, the main reason given was they do not have enough milk' (Table 3). Many mothers (69\%) also thought that 'having to go to work or study' was a major reason to stop breast-feeding or 'having a disease' or 'being on strong medication'. Only a very few mothers thought that mothers stop breast-feeding because 'formula is better' or 'due to the influence of grandmothers, friends or other relatives'.

Almost all of the mothers (94\%) decided to breastfeed because 'breast milk is better' (Table 4). Motherinfant bonding is highly valued by Maldivian mothers, as shown by $77 \%$ deciding to breast-feed because

Table 2 Length of time after birth before the baby was put to the breast

\begin{tabular}{lrr}
\hline & $n$ & $\%$ \\
\hline Immediately after birth $(<1 \mathrm{~h})$ & 134 & 53 \\
Within a few hours & 90 & 36 \\
Within 24h & 20 & 8 \\
Next day & 2 & 1 \\
Missing & 5 & 2
\end{tabular}


504

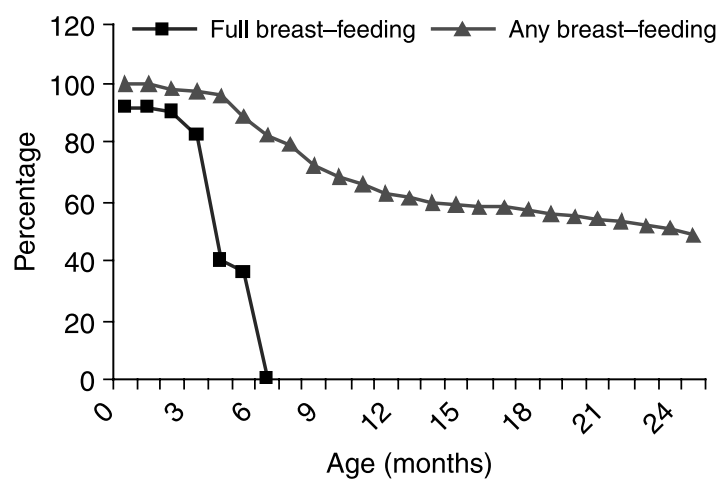

Fig. 1 Maldives breast-feeding rates

breast-feeding promotes mother-infant bonding. Many mothers (62\%) decided to breast-feed because breastfeeding is more convenient. Only $4 \%$ of mothers indicated that they would breast-feed because it is a part of their religion.

The respondents were also asked about methods that mothers in the Maldives use to produce more milk; about half (53\%) indicated that they did nothing. About one-third (30\%) of mothers said they ate healthy meals and drank lots of fluids, including milk. Coconut milk was used as a drink to increase breast milk by $14 \%$ of mothers and two mothers used traditional medicine.

A majority (60\%) of mothers stated that they decided how they were going to feed their baby after the baby was born, 16\% before getting pregnant and only 14\% early in their pregnancy (Table 5). However, this has to be seen in the context of a culture where breast-feeding is universal and mothers would not have been thinking of anything other than breast-feeding. Most of the fathers supported breast-feeding.

Smoking is not common among Maldivian women; only $2 \%$ of mothers smoked before getting pregnant and only one mother smoked while pregnant. However, the smoking rate for males is much higher and 37\% of fathers smoked before their wife's pregnancy and almost of all of these continued smoking during pregnancy and breastfeeding.

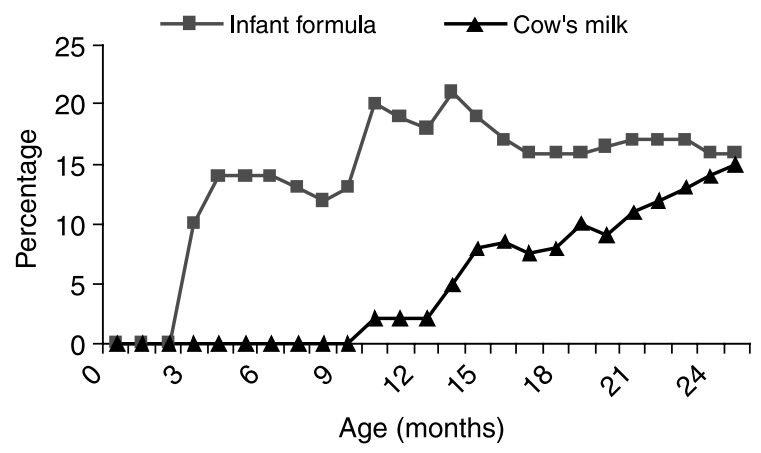

Fig. 2 Consumption of infant formula and cow's milk
R Abdulraheem and CW Binns

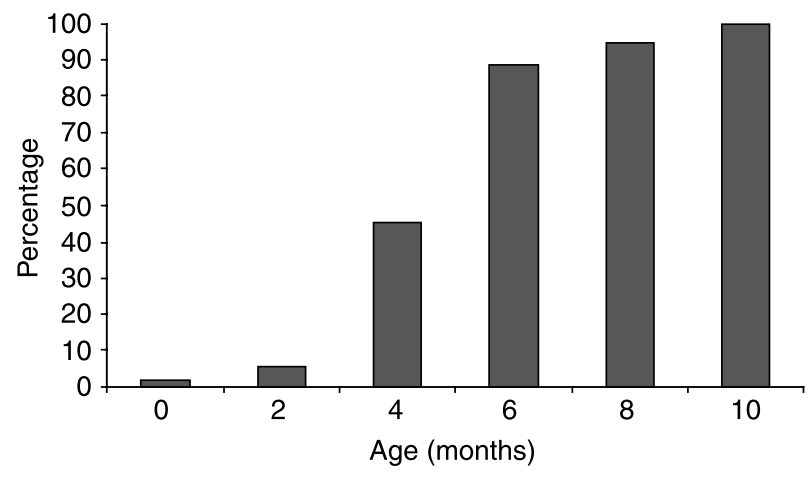

Fig. 3 Age of introduction of solid foods

\section{Discussion}

The exclusive breast-feeding rate in the Maldives in infants aged $0-3$ months was reported to be $8 \%$ in $1991^{21}$. In the present study the rates of 'any breast-feeding' were high, with $100 \%$ of mothers breast-feeding on discharge from hospital and $85 \%$ breast-feeding at 6 months. These rates are comparable with the highest rates found in developing countries $^{22,23}$. However, the 'full breast-feeding' rates are well below the World Health Organization's target of every baby being exclusively breast-fed for the first six months, although it is government policy to promote exclusive breast-feeding. Maldives is a Muslim country and breastfeeding is an important part of the Islamic religion. In other Muslim countries, such as the rural and semi-urban communities in Kemaman, Terengganu, Malaysia, high rates of breast-feeding are encouraged by Islamic teachings, the religion of the community ${ }^{24}$.

Infant formula was given to babies as early as 1 month in the Maldives. However, this practice is not common and high rates of breast-feeding continued (Fig. 1). The earliest age Maldivian mothers gave their infants cow's milk was 7 months. From 7 months onwards there was a gradual increase in the percentage of mothers giving cow's milk. In a study in Iraq, another Islamic country, of 694 children (392 males and 302 females), 14.4\% were receiving infant formula in addition to breast milk by the age of 6 months ${ }^{25}$. This is a similar rate to the present study. In the Maldives most mothers introduced solid food to their

Table 3 Reasons cited by Maldivian mothers for mothers to stop breast-feeding before 6 months

\begin{tabular}{lr}
\hline & $\%$ \\
\hline Not enough milk & 75.3 \\
Mother has to go to work or study & 68.5 \\
Mother has illness or is on strong medication & 12.4 \\
Mother wants to continue smoking & 5.2 \\
Health workers suggest bottle-feeding & 4.4 \\
Mother finds breast-feeding too painful & 4.4 \\
Baby's father disapproves & 4.0 \\
Mother plays a lot of sports & 3.6
\end{tabular}

Note: more than one answer could be given. All mothers gave at least one answer. 
Table 4 Reasons why Maldivian mothers decided to breast-feed

\begin{tabular}{lc}
\hline & $\%$ \\
\hline Breast milk is better for the baby & 93.6 \\
Breast-feeding promotes mother-infant bonding & 76.9 \\
Breast-feeding is more convenient & 61.8 \\
Breast-feeding is natural & 58.6 \\
Breast-fed babies are more intelligent & 55.0 \\
Breast-fed infants have fewer infections & 34.7 \\
The baby's father wanted me to breast-feed & 19.1 \\
Breast-feeding is cheaper & 17.9 \\
Breast-feeding helps you lose weight & 13.5 \\
Other people advised me to breast-feed & 6.0 \\
My mother advised me to breast-feed & 5.6 \\
Religion & 4.4 \\
\hline
\end{tabular}

Note: more than one answer could be given. All mothers gave at least one answer.

infants at the age of 4 months and this might be because the recommended duration for exclusive breast-feeding in the Maldives was formerly 4 months.

The main reason given by Maldivian mothers for mothers to stop breast-feeding and also introduce the bottle before 6 months was because they 'do not have enough milk'. Mothers were concerned that having not enough milk will influence their infant's growth. Maldivian mothers are relatively small in size and yet want their babies to grow bigger, leading them to become anxious about their milk supply. This is similar to surveys in Western Australia and Jamaica where mothers indicated the main reason for stopping breast-feeding is because they fear that there is insufficient breast milk for the baby $^{19,26,27}$.

Many mothers in Maldives cited 'having to go to work or studies' as a major reason to stop breast-feeding and also for introducing the bottle. However, in this study most of the mothers who were working were still breast-feeding. The Maldivian government supports mothers to breast-feed their children and working mothers who have an infant are allowed to go home during working hours to breast-feed the child. Mothers are also given maternity leave which is of 2 to 3 months' duration, when holidays are included.

While the Maldivian mothers gave a number of different explanations for why they felt women stop breast-feeding, almost all of the mothers chose breast-feeding. The main reasons for Maldivian mothers choosing to breast-feed were because breast milk is better, breast-feeding promotes mother-infant bonding, breast-feeding is more convenient, breast-feeding is natural and because breastfeeding makes the baby more intelligent. Maldivian mothers believed that breast-feeding is good because it is encouraged in their religion. It is a traditional saying in the Maldives that 'breast-fed babies will love their parents, but if babies are given cow's milk they will not obey parents'.

In addition, the present results show that Maldivian mothers want to breast-feed their infants during night time. Most mothers indicated that a mother should keep the baby in the same room so that it is easier to
Table 5 Factors influencing breast-feeding

\begin{tabular}{lr}
\hline & \\
\hline & $\%$ \\
\hline Time when Maldivian mothers first decided how they were going \\
to feed their baby & 13.5 \\
Early in pregnancy & 9.6 \\
Late in pregnancy & 59.4 \\
After baby was born & \\
Place Maldivian mothers think a newborn baby should sleep & 32.7 \\
In the same bed as mother (easier to breast-feed) & 65.3 \\
In the same room but different bed (to prevent accidents) & 0.8 \\
In a different room & \\
Sources of information on breast-feeding & 37.1 \\
Pamphlets or booklets on breast-feeding & 6.4 \\
Sessions or classes on breast-feeding & 69.3 \\
Videos or television shows on how to breast-feed & 44.2 \\
Individual consultation or discussion & 5.6 \\
None & 8.4 \\
Other (e.g. Western magazines and books) & \\
People who support or encourage Maldivian mothers with & breast- \\
feeding & \\
Baby's father & 66.1 \\
Mother's mother & 45.8 \\
Mother's mother-in-law & 19.1 \\
Other member of baby's mother's family & 19.1 \\
Doctors or nurses & 37.8 \\
Others & 5.2 \\
Did your mother breast-feed any of her children? & 84.5 \\
Yes & 8.8 \\
No & 5.6 \\
Do not know & \\
Did the baby's father have any preference for how you fed your \\
baby?
\end{tabular}

breast-feed. However, most mothers said the baby should be in a different bed so that the baby does not get under the mother's body. Still, one-third of the mothers thought babies should be in the same bed with the mother so it is easier to breast-feed when the mother is tired. In England, Blair and Ball ${ }^{27}$ collected data on night-time sleeping practices from a 2-year local longitudinal study and a 3-year national cross-sectional study. A total of 261 infants in North Tees were followed up at 1 and 3 months of age, as were 1095 infants aged 1 week to 1 year from five English health regions ${ }^{27}$. Data from both studies revealed that almost half of all neonates bed-shared at some time with their parents (local: 47\%, 95\% confidence interval (CI) 41-54\%; national: 46\%, 95\% CI 34-58\%), and on any one night in the first month over a quarter of parents slept with their baby (local: 27\%, 95\% CI 22-33\%; national: 30\%, 95\% CI 20-42\%). In the present study too, breastfeeding was found to be strongly associated with bedsharing, both at birth and at 3 months of age. 
An important factor which helps Maldivian mothers' initiation and duration of breast-feeding is the information provided at health centres. More than $75 \%$ of the mothers said that there is enough information provided by the health centres. Mothers indicated that the main sources information were through radio and television and also from health centres. However, only a very few mothers indicated that they got information from breast-feeding classes or sessions. In other countries, lactation centres are known to be very effective in providing information on breast-feeding ${ }^{28}$.

In this Maldivian study the baby's fathers were first on the list in supporting and encouraging breast-feeding. Also, $85 \%$ of mothers said that the baby's father preferred breast-feeding. This shows the support that Maldivian fathers give for their children to be breast-fed. This is consistent with studies in other countries. A cross-sectional survey of 506 Mandarin-speaking women in Perth, Western Australia, conducted to identify determinants of the initiation and duration of breast-feeding by Chinese Australian mothers, showed that father's preference for breast-feeding was positively associated with the initiation of breast-feeding (odds ratio: 4.96, 95\% CI 1.93-12.66) ${ }^{29}$.

In the Maldives $85 \%$ of mothers also said that their own mothers breast-fed their children. Almost half of the mothers said that they also encouraged and supported breast-feeding and $82.5 \%$ of mothers said that their mothers preferred breast-feeding. Likewise, a study by Isabella and Isabella indicated that husbands and (grand) mothers provided the greatest degree of emotional and instrumental support, while doctors and nurses provided more information, which was also associated with success at establishing lactation ${ }^{30}$. Mothers who were themselves breast-fed as infants nursed their infants more at 1 month than those who were bottle-fed. The factors vary in different cultures and a trial would be needed to quantify which interventions would be most relevant in education programmes in the Maldives.

There are a number of limitations that should be considered when interpreting the data in this paper. This study was undertaken on only one atoll (Kaafu atoll), even though this is where most of the population and particularly the more educated people live. While the results are likely to be representative of the situation on the other islands, further studies will be needed to confirm this. Ideally, to gain more detailed knowledge of breastfeeding practices in the Maldives, a longitudinal cohort study of a larger sample size is required.

\section{Conclusions and recommendations}

Breast-feeding is very important to both the mother and child because of the medical, social, psychological and economic benefits. The present study in the Maldives showed that 'any breast-feeding' initiation and duration of breast-feeding are high. In addition, 'full breast-feeding rates' before 4 months is also high. This results from the belief of Islam which, through the Koran, provides Muslims with clear instructions to suckle their children for two whole years. The challenge is to sustain these high rates and to increase the rate of exclusive breast-feeding while the Maldives is going through rapid socio-economic growth and infant formula is becoming readily available. Although Maldivian health workers discourage the promotion of milk substitutes, there are no real laws restricting their promotion.

To promote breast-feeding it is necessary to understand the attitudes, knowledge and factors associated with breast-feeding. The results of the present study will provide information for the basis of a health promotion programme for breast-feeding and to promote extensions to maternity leave for mothers. A larger cohort study would provide additional information that would assist in maintaining breast-feeding rates.

\section{Acknowledgements}

We thank AusAID, the Faculty of Health Sciences of the Maldives College of Higher Education and Curtin University School of Public Health for the resources to undertake this survey. We also thank Ministry of Health, the health centres and the mothers who participated in this survey for their support and cooperation.

\section{References}

1 Binns C, Davidson G. Infant feeding guidelines for health workers. In: National Health \& Medical Research Council, ed. Dietary Guidelines for Children and Adolescents in Australia incorporating the Infant Feeding Guidelines for Health Workers Canberra: Commonwealth of Australia, 2003.

2 Butte NF, Lopez-Alarcon MG, Garza C. Nutrient Adequacy of Exclusive Breastfeeding for the Term Infant During the First Six Months of Life. Geneva: World Health Organization, 2002.

3 Anderson J, Johnstone B, Remley D. Breast-feeding and cognitive development: a meta-analysis. American Journal of Clinical Nutrition 1999; 70(4): 525-35.

4 World Health Organization (WHO). Global Strategy for Infant and Young Children Feeding. Geneva: WHO, 2003.

5 WHO Collaborative Study Team on the Role of Breastfeeding on the Prevention of Infant Mortality. Effect of breastfeeding on infant and child mortality due to infectious diseases in less developed countries: a pooled analysis. Lancet 2000; 355(9202): 451-5.

6 Binns C, Lee MK, Oddy WH. Breastfeeding and the prevention of obesity. Asia Pacific Journal of Public Health 2003; 15(Suppl.): S22-6.

7 Armstrong J, Reilly JJ; Child Health Information Team. Breastfeeding and lowering the risk of childhood obesity. Lancet 2003; 359(9322): 2003-4.

8 Kramer MS, Kakuma R. The Optimal Duration of Exclusive Breastfeeding: A Systematic Review. Geneva: World Health Organization, 2002.

9 Dewey K, Heinig M, Nommsen L. Maternal weight-loss patterns during prolonged lactation. American Journal of Clinical Nutrition 1993; 58(2): 162-6.

10 Collaborative Group on Hormonal Factors in Breast Cancer. Breast cancer and breastfeeding: collaborative reanalysis of 
individual data from 47 epidemiological studies in 30 countries, including 50302 women with breast cancer and 96973 women without the disease. Lancet 2002; 360(9328): 187-95.

11 Zhang M, Lee AH, Binns CW. Prolonged Lactation Reduces Ovarian Cancer Risk in Chinese Women. Perth, WA: Curtin University of Technology, 2002.

12 Tommaselli GA, Guida M, Palomba S, Barbato M, Nappi C. Using complete breastfeeding and lactational amenorrhoea as birth spacing methods. Contraception 2000; 61(4): $253-7$.

13 American Academy of Pediatrics. Breastfeeding and the use of human milk. Pediatrics 2005; 115(2): 496-505.

14 World Health Organization (WHO). Exclusive breastfeeding. Child and Adolescent Health and Development. Geneva: WHO, 2000.

15 World Health Organization (WHO). The World Health Report 2005: Make Every Mother and Child Count. Geneva: WHO, 2005.

16 United Nations Children's Fund (UNICEF). The State of the World's Children 2006. New York: UNICEF, 2006.

17 Graham K, Scott J, Binns C, Oddy W. National targets for breastfeeding at hospital discharge have been achieved in Perth. Acta Paediatrica 2005; 94(3): 352-6.

18 Scott JA, Binns CW, Aroni R. Infant Feeding Practices in Perth and Melbourne. Report for the National Better Health Promotion Program. Perth, WA: Curtin University, November 1995.

19 Binns C, Scott J. Breastfeeding: reasons for starting, reasons for stopping and problems along the way. Breastfeeding Review 2002; 10(2): 13-19.

20 Australian Bureau of Statistics (ABS). National Health Survey 2001: Summary of Results. Catalogue No. 4364.0. Canberra: ABS, 2002.
21 World Health Organization. Country Profiles: South East Asia [online], 1991. Available at http://www.whosea.org/nhd/ pdf/49-52.pdf. Accessed October 2005.

22 Lakati A, Binns C, Stevenson M. Breast-feeding and the working mother: the Kenya experience. Public Health Nutrition 2002; 5(6): 715-8.

23 Binns CW. Food, sickness and death in children of the highlands of Papua, New Guinea. Journal of Tropical Pediatrics and Environmental Child Health 1976; 22(1): 9-11.

24 Yusof YA, Mazlan M, Ibrahim N, Jusoh NM. Infant feeding practices and attitudes of mothers in Kelantan towards breastfeeding. Medical Journal of Malaysia 1995; 50(2): $150-5$.

25 Benyamen YS, Hassan MK. Feeding patterns in the first two years of life in Basra, Iraq. Eastern Mediterranean Health Journal 1998; 4(3): 448-51.

26 Chatman LM, Salihu HM, Roofe ME, Wheatle P, Henry D, Jolly PE. Influence of knowledge and attitudes on exclusive breastfeeding practice among rural Jamaican mothers. Birth 2004; 31(4): 265-71.

27 Blair PS, Ball HL. The prevalence and characteristics associated with parent-infant bed-sharing in England. Archives of Disease in Childhood 2004; 89(12): 1106-10.

28 Barros FC, Semer TC, Tonioli Filho S, Tomasi E, Victora CG. The impact of lactation centres on breastfeeding patterns, morbidity and growth: a birth cohort study. Acta Paediatrica 1995; 84(11): 1221-6.

29 Li L, Zhang M, Scott JA, Binns CW. Factors associated with the initiation and duration of breastfeeding by Chinese mothers in Perth, Western Australia. Journal of Human Lactation 2004; 20(2): 188-95.

30 Isabella PH, Isabella RA. Correlates of successful breastfeeding: a study of social and personal factors. Journal of Human Lactation 1994; 10(4): 257-64. 